\title{
Filistorias
}

(PPGHIS/UnB) No. 35, Brasília, Jul - Dez 2019 ISSN 2316-1191

Recebido: $22 / 10 / 2019$

Aprovado: 13/02/2020

DOI: 10.26512/emtempos.vi35.27702

\section{O tempo mítico nos fanzines de heavy metal}

\author{
José Eduardo Oliveira Nascimento \\ Mestrando em História do Brasil na UFPI \\ edumetal18@gmail.com \\ Edwar Castelo Branco \\ Doutor em História \\ Professor na Universidade Federal do Piauí \\ edwar2005@uol.com.br
}

Resumo: $O$ presente artigo tem como objetivo identificar e analisar narrativas míticas nos fanzines de heavy metal que circularam na cidade de Teresina no período entre 2000 à 2014. Pretendemos problematizar as técnicas de sujeição dos headbangers através dos fanzines. No trabalho os fanzines de heavy metal aparecem como "textos prescritivos" que configuram a década de 1980 como um tempo mítico provocando atrito com as técnicas de subjetivação no contexto do heavy metal. Para o estudo do objeto aqui proposto o trabalho se beneficiou das noções de José Carlos Reis (2007) sobre o conceito de tempo histórico e, bem como, das noções de sujeito presentes numa ampla literatura pós-estruturalista e notadamente em Michel Foucault (2017). A intenção do estudo é, a partir da leitura sistemática de fanzines, entender o papel do tempo mítico no contexto do heavy metal.

Palavras-chave: História; Fanzines; Tempo mítico. 


\begin{abstract}
This article aims to identify and analyze mythical narratives in the heavy metal fanzines that circulated in the city of Teresina from 2000 to 2014 . We intend to problematize the techniques of subjecting the headbangers through the fanzines. In the work the heavy metal fanzines appear as "prescriptive texts" that configure the 1980 s as a mythical time causing friction with subjectivation techniques in the context of heavy metal. For the study of the object proposed here, the work benefited from the notions of José Carlos Reis (2007) about the concept of historical time, as well as the notions of subject present in a wide poststructuralist literature and notably Michel Foucault (2017). . The intention of the study is, from the systematic reading of fanzines, to understand the role of mythic time in the context of heavy metal. Keywords: History; Fanzines; Mythical time.
\end{abstract}

\title{
Introdução
}

(...) os zines são atemporais, retratam a cena de uma determinada época e espaço, congelam o momento como se fosse uma fotografia underground.

Pecatório zine, 2012.

Dentre todas as conceituações acadêmicas sobre os fanzines $^{l}$, a definição que melhor se adéqua aos objetivos do presente estudo é aquela constante da epígrafe deste artigo: se história implica um tempo, o fanzine complica este parâmetro narrativo, na medida em que esta mídia underground ${ }^{2}$ é atemporal. Assim sendo, consideramos assertiva a afirmação da característica atemporal do zines, pois, sobretudo, são mídias que distorcem, borram e implodem as noções tradicionais de tempo e espaço.

Tal característica torna necessário esclarecer alguns pontos pertinentes para a compreensão do presente texto: os fanzines são fontes históricas privilegiadas para (re)pensarmos as categorias centrais de trabalho do historiador, vez que são fontes que não encontram fácil enquadramento na História. Sobre esta característica Castelo Branco já argumentou que:

\footnotetext{
${ }^{1}$ MAGALHÃES, Henrique. O que é fanzine. São Paulo, SP: Editora Brasiliense, 1993. MUNIZ, Cellina (org). Fanzines: autoria, subjetividades e invenção de si. Fortaleza: Edições UFC, 2010. CASTELO BRANCO, Edwar de Alencar. Mídias táticas: os fanzines como fontes para a pesquisa histórica. In: Diálogos (Maringá. Online), v.19, n.2, p.741-762, mai-ago./2005.

${ }^{2}$ Esse espaço, (...) se caracteriza como um conjunto de práticas urbanas que constroem alternativas de produção artística que não estão atrelados a lógica capitalística de subjetividades (...). Para mais informações: NASCIMENTO, José Eduardo Oliveira. O cara mais underground é o diabo: representações, sentidos e subjetividades sobre o diabo no rock metal extremo de Teresina entre 2005-2017. 2018. 92 f. Monografia (Licenciatura Plena em História). Universidade Estadual do Piauí, Campo Maior, 2018. p.13-14
}

\section{Filstotorias}


(...) à primeira vista o tratamento deste universo, do ponto de vista da escrita da história, é problemático: por um lado, o fanzine é aperiódico, com distribuição precária e editado com poucos recursos financeiros. (...) Isto cria uma dificuldade de ordem metodológica que é justamente estabelecer a autoria e, em muitos casos, o tempo e o lugar de onde este material está falando. (...) No caso dos fanzines, os fios da vida-particularmente visíveis nos fanzines temáticos - curto-circuitam e explodem deliberadamente os fios da obra. (CASTELO BRANCO: 2005: 755-756).

Portanto, o fanzine é uma fonte histórica com peculiaridades que devem ser levadas em consideração durante a análise. Assim, o presente artigo visa debater o tempo nos fanzines de heavy metal a partir de uma perspectiva mitológica. Mas por que apenas os fanzines de heavy metal? Ora, genericamente, os fanzines podem ser definidos na perspectiva de Henrique Magalhães:

(...) O termo fanzine é um neologismo formado pela contração dos termos ingleses fanatic e magazine (...) $\mathrm{O}$ fanzine é uma publicação alternativa ou amadora, geralmente de pequena tiragem e impressa artesanalmente. É editado e produzido por indivíduos, grupos ou fãs clubes de determinada arte, personagem, personalidade, hobby ou gênero de expressão artística, para um público dirigido e abordando, quase sempre, um único tema. (MAGALHÃES: 1993:08).

Um estudo histórico sobre os fanzines exige atenção às singularidades da cultura zineira, pois, dependendo da forma, tema e conteúdo abordado, os fanzines são bastante díspares entre si, pois como afirma Silva, os fanzines de heavy metal são caracterizados por:

(...) uma preocupação clara em mostrar profissionalismo e seriedade no que se faz e fala. Não há muito espaço para ironia nos editoriais, que em muitos casos, prefere focar em descrições de eventos, resenhas, entrevistas com as bandas, em formato semelhante ao de revista. Enquanto os fanzines punks costumam ser mais debochados, de diagramação difusa e não buscam ter fins lucrativos, o material produzido para o headbanger procura passar uma mensagem mais direta, profissional e aproximada das mídias convencionais. (SILVA: 2016: 95).

Portanto, ao analisar os fanzines é necessário levar em consideração sua forma e seu conteúdo. Entendemos que para cada tipo de zine existe um tempo predominante em sua narrativa. O tempo como construção cultural, ou seja, o tempo aqui é estudado como percepções que variam historicamente, assim, cada contexto histórico tem uma percepção temporal dominante. Por conseguinte, dependendo do contexto cultural no qual o fanzine foi produzido, existe uma narrativa sobre o tempo que predomina no espaço do fanzine. Sobre essas percepções do tempo recorremos a José Carlos Reis:

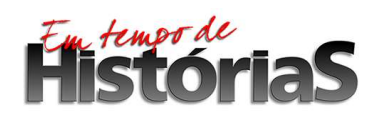


Essa diversidade de "dizeres do tempo" deve-se também ao fato de que a experiência da temporalidade não é jamais direta, um vivido imediato e mudo, mas sempre articulada por sistemas simbólicos variados. O tempo "como tal" fica mais distante: além de só existir em relação a um discurso teórico, disciplinado, a experiência mesma do tempo, o vivido, é mediado por um sistema simbólico, por uma cultura. (REIS: 1994: 13).

Desse modo, identificamos nos fanzines de heavy metal uma narrativa mitológica sobre o tempo. Assim, vamos concentrar nosso debate no tempo dos zines tendo como fio condutor a seguinte hipótese: os headbangers, utilizando os fanzines como um elemento de sujeição, representam um tempo mitológico que, por consequência, acaba interferindo nas técnicas de subjetivação dos mesmos. Mas por que os fanzines como fontes?

Escolhemos os fanzines para análise, porque estas mídias são, historicamente, um dos principais meios de comunicação utilizados pelos headbangers, além de ser uma fonte privilegiada para compreender as formas de sujeição e subjetivação dos headbangers. Mas quem são os headbangers? O que são essas formas de sujeição e subjetivação? Bom, respectivamente, o termo headbanger foi utilizado para identificar os fãs de heavy metal que começavam a "bangear" a cabeça no ritmo das músicas. Silva comenta:

Embevecidos pela sonoridade característica, seus apreciadores costumam balançar a cabeça para frente e para trás, acompanhando o ritmo das músicas. Esse movimento corporal, que começou a ser observado nos shows durante a década de 70 , se mostrou tão peculiar e se propagou de tal forma ao longo dos anos que serviu para batizar genericamente os fãs de heavy metal como headbangers (...) (SILVA: 2008:16).

No Brasil, o termo foi utilizado após o Rock in Rio, em 1985, em oposição ao termo metaleiro $^{3}$, popularizado pela Rede Globo. Já as formas de sujeição e subjetivação são entendidas aqui à maneira de Michel Foucault, ou seja, sujeição é “(...) a maneira pela qual o indivíduo estabelece sua relação com essa regra e se reconhece como ligado à obrigação de pô-la em prática" (FOUCAULT: 2018:34), e subjetivação são “procedimentos e as técnicas pelas quais são elaboradas, aos exercícios pelos quais o próprio sujeito se dá como objeto a conhecer, e as práticas que permitam transformar seu próprio modo de ser" (FOUCAULT: 2018:38).

${ }^{3}$ Ver: BRANDÃO JR, Ernani José. Headbanger: a produção histórica de uma subjetividade extrema. $2007.77 \mathrm{f}$. Monografia (graduação) - Centro de Ciências Humanas e Letras, Universidade Estadual do Piauí - UESPI, Teresina, 2007. 
Assim, na perspectiva que estamos adotando, os fanzines de heavy metal são entendidos como textos prescritivos por "propor regras de conduta" (FOUCAULT: 2018: 18) que sujeitam os headbangers a determinas práticas. Ao contrário disso, as técnicas de subjetivação têm por característica um trabalho sobre si como modo de metamorfosear o próprio ser. Para tal tarefa selecionamos os seguintes zines: Metal Warrior, Pecatório zine, Sindicatos dos assassinos e Metal of the nation. Todos os zine selecionados circularam em Teresina - PI entre a primeira e o início da segunda década dos anos 2000.

\section{O mito do heavy metal}

Inicialmente, é preciso elucidar e explanar sobre o quê, de fato, são os mitos. Julgamos necessário esse debate, pois os mitos são significantes que atuam em várias culturas ao redor do mundo, seja na esfera política, econômica, social ou religiosa. Assim, esclarecer a função do mito é pertinente para compreendermos como seus mecanismos operam no contexto dos fanzines de heavy metal. Recorremos a Girardet quando ele argumenta que o mito deve ser:

(...) concebido uma narrativa: narrativa que se refere ao passado ("Naquele tempo...", "Era uma vez..."), mas que conserva no presente um valor eminentemente explicativo, na medida em que esclarece e justifica certas peripécias do destino do homem ou certas formas de organização. (...) conta uma história sagrada; relata um acontecimento que teve lugar no tempo imemorial, o tempo fabuloso dos começos. Em outras palavras, o mito conta como uma realidade chegou à existência (...) (GIRARDET: 1987: 12-13).

O mito é, pois, uma narrativa que busca esclarecer a origem existencial de determinado grupo cultural. Nesse caso, o mito headbanger se configura como um elemento tão forte nas sociabilidades que está inibindo as técnicas de subjetividade, assim, o headbanger fica fadado há uma existência cristalizada. Mas qual é o mito que está freando as técnicas de subjetivação dos headbangers? Bom, para tentar esclarecer essa questão vamos, agora, nos debruçar sobre os fanzines.

O primeiro fanzine que iremos analisar é o Metal Warrior. Como nos alertou Silva, chama atenção à estética mais "profissional" do fanzine selecionado. Contrariando muitas conceptualizações acadêmicas o zine Metal Warrior usa um conceito estético que nos remete 
as revistas de grande circulação comercial. Esse fanzine nos aponta para uma captura social ${ }^{4}$ das subjetividades rompendo, assim, com a estética ${ }^{5}$ desviante dessa mídia underground. Enfim, esse é um debate para outro artigo. O que nos importa agora é identificar como o fanzine articula o tempo em prol de uma narrativa mitológica. Para começar, selecionamos dois trechos. Respectivamente, entrevista realizada com a banda Oráculo e uma matéria sobre a banda piauiense Steel Danger.

(...) Brother, eu não vou longe, na década de 80 e 90 em Fortaleza haviam muitas bandas, bandas de grandes qualidades tinham muitas mesmo, e hoje são poucos, mas as que estão atuando, como nós do Oraculo correm atrás do sonho. ${ }^{6}$

Depois de alguns anos atuando na cena heavy metal teresinense em bandas autorais e covers, sentiu-se a necessidade de próprio dentro das raízes do heavy metal tradicional dos anos 80, se engajando numa tentativa de resgatar a grande época que a cena teresinense viveu décadas atrás. Fortemente influenciada por nomes como Black Sabbath, Dio, Judas Priest $(\ldots)^{7}$

Primeiramente, é interessante observar que ambas os trechos destacados dão ênfase a década de 1980. Além disso, existe no discurso do entrevistado e, também, na matéria sobre a Steel Danger, um senso de resgate por algo que está sendo perdido dentro da "cena atual". Utiliza-se essa narrativa como forma de hierarquizar as bandas de heavy metal. Isso pode ser identificado quando o entrevistado diz que "80 e 90 em Fortaleza haviam muitas bandas, bandas de grandes qualidades tinham muitas mesmo, e hoje são poucos (...)”, assim, de forma implícita, o entrevistado faz uma distinção qualitativa das bandas com base no tempo, ou seja, o tempo se configura como um critério de status. Esse tempo mítico é constantemente reproduzido nos fanzines de heavy metal. Desse modo, os fanzines acabam por minar outras formas de ser/estar/ouvir/produzir heavy metal e sujeita o headbanger a uma narrativa mítica sobre o heavy metal oitentista. Um exemplo de técnicas de sujeição é a imagem da banda Eternal Violence que extraímos do webzine ${ }^{8}$ Sindicatos dos Assassinos. Para reforçar essa tendência, vamos comparar com uma foto da banda brasileira Sepultura da década de 1980.

\footnotetext{
${ }^{4}$ Para mais detalhes, ver: CASTELO BRANCO, Edwar de Alencar. Todos os dias de paupaeria: Torquato Neto e uma contra-história da tropicália. 2004. 289 f. Tese (Doutorado em História) - Universidade Federal de Pernambuco - UFPE, 2004.

${ }^{5}$ Folha A4, colagens, preto e branco, subversão da escrita formal e etc.

${ }^{6}$ Metal Warriors Maganize. Ed. 9 ${ }^{\circ}, 2014$. P.08.

${ }^{7}$ Metal Warriors Maganize. Ed. 9, 2014. P.16. Negrito nosso.

${ }^{8}(\ldots)$ circulam através das redes sociais, ou seja, fanzines que são feitos através de ferramentas digitais e possuem uma estética mais "profissional" e são disponibilizados on-line para os leitores em plataformas digitais.
} 


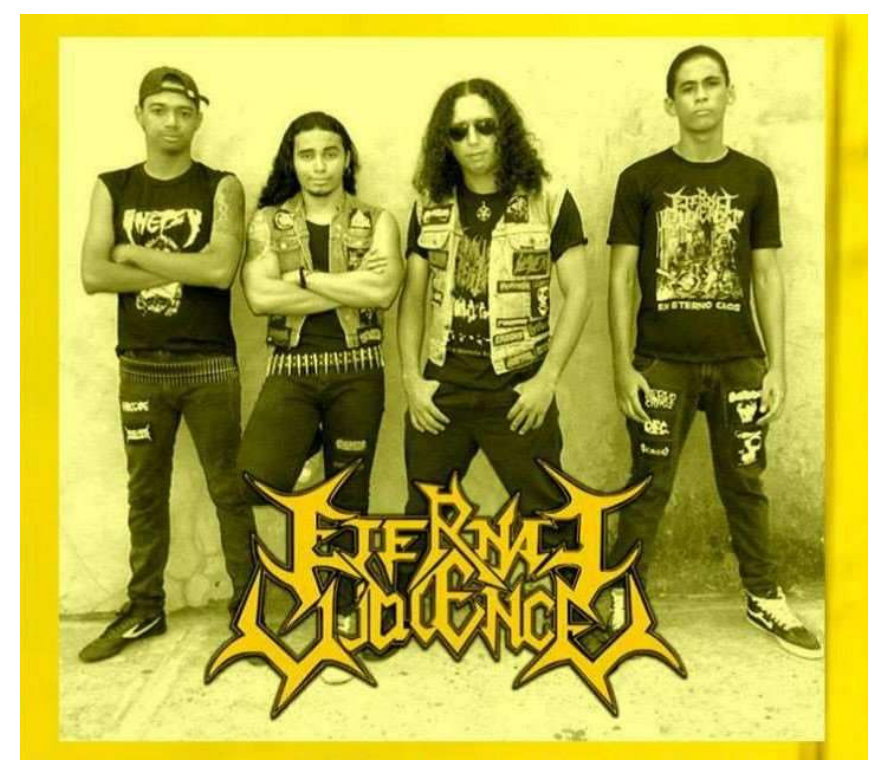

Apesar da distância cronológica que separa a foto da década de 1980, percebe-se muitas características similares com os headbangers da década citada. A estética das roupas, objetos, os símbolos que os indivíduos ostentam em suas vestimentas compõem o que podemos chamar de técnicas de sujeição headbanger, ou seja, é um conjunto de condutas mais ou menos explícitas que circula no contexto do heavy metal e, na qual, o sujeito trabalha a si mesmo para ser reconhecido como headbanger. Assim, o visual em questão não é uma simples roupa, mas um uniforme, um "modus de vestir" headbanger.

Essa estética nos remete diretamente ao visual oitentista adotado pelas bandas da época como, por exemplo: coletes de pacth ${ }^{10}$, camisas pretas, cintos de balas, calças jeans “surradas". A respeito dessa estética Campoy diz: "Calças pretas coladas ou calças jeans rasgadas, tênis branco e o "clássico" colete jeans com patches costurados. A indumentária apresentada (...) figura no imaginário do metal extremo underground como qualquer coisa de ancestral (...)"(CAMPOY: 2008: 114).

Portanto, apesar de distantes cronologicamente os headbangers usam técnicas de sujeição como forma de evasão temporal ${ }^{11}$, onde buscam um religare com esse "tempo

NASCIMENTO, José Eduardo Oliveira. O cara mais underground é o diabo: representações, sentidos e subjetividades sobre o diabo no rock metal extremo de Teresina entre 2005-2017. 2018. 92 f. Monografia (Licenciatura Plena em História). Universidade Estadual do Piauí, Campo Maior, 2018. P.14.

${ }^{9}$ Fonte: Sindicato dos Assassinos, N 01, 2014.

${ }^{10}$ Pequenos pedaços de tecido com logo de bandas que são costurados nos coletes e nas calças jeans.

${ }^{11}$ Ver: REIS, José Carlos. Tempo, história e evasão. Campinas, Sp: Papirus, 1994.

\section{Filistorias}


perdido". Dessa maneira, os headbangers experimentam o tempo como "tempo terror". Sobre isso Castelo Branco comenta:

(...) o tempo é causador de medo, angústia e dor, posto que as sociedades humanas "aspiram sempre a eternidade, à estabilidade, à unidade, a um presente eterno" (REIS, 1994b: 143). Esta aspiração tem historicamente levado estas mesmas sociedades a evadirem-se deste tempo-terror através de representações de tempo (...) (CASTELO BRANCO: 2001: 05).

Identificamos nas narrativas dos fanzines de heavy metal uma forma de repetir o momento "axial", ou seja, a partir de um começo original busca-se "suspender" o tempo e experimentar um eterno presente. Nos fanzines analisados o futuro é ignorado. Os headbangers não visam construir uma nova ruptura, outro momento "axial", ao contrário, é no tempo do mito, qual seja, a década de 1980, que deverá ser revivido a "essência" headbanger. José Carlos Reis argumenta:

(...) repetição ininterrupta de gestos inaugurais. Ele repete gestos paradigmáticos, buscando uma participação em uma realidade transcendente. (...) Por meio de rituais, o caos dos eventos é integrado no cosmos. Sacralizando, os eventos ganham realidade e sentido. A sacralização se dá pelo ritual - um altar, um sacrifício, um canto, danças, palavras especiais repetidas. $\mathrm{O}$ ritual é a repetição do ato cósmico da criação. $\mathrm{O}$ tempo do ritual coincide com o tempo mítico do começo. Pela repetição-ritual do ato criador, o hoje concreto é suspenso (...) o presente se une ao passado em um presente intenso, em um instante eterno. (REIS: 1994:144).

Dominados por essa concepção mítica do tempo os fanzines de heavy metal acabam minando tentativas de subjetivação de sujeitos que não se enquadram nos estereótipos que buscam repetir "gestos inaugurais", assim, como "punição", a identidade de "headbanger de verdade" lhes é negada. Nesse julgamento, o tempo do mito é o juiz, investigador e o carrasco. O mito como conservador de um status quo no contexto cultural do heavy metal também é identificado por Campoy. Ele nos chama atenção ao argumentar que:

O principal artifício para atestar o estatuto do real e do falso é o tempo de inserção no underground. A participação da pessoa nas práticas deste espaço por um longo período de tempo é usada como um recurso para "revelar" a realidade ou falsidade da pessoa. (...) Mas o que confere poder ao "veterano" é seu longo tempo de inserção no underground. Ele sabe manipular sua biografia, se mostrar e ser visto como alguém que por muito tempo pratica as atividades deste espaço. (CAMPOY: 2008: 81-82). 
As bandas de qualidade e os headbangers de confiança são aqueles que ostentam consigo a estética do "tempo perdido", ou seja, a década de 1980. Dessa forma, se produz uma narrativa que coloca a década de 1980 como o "mito headbanger". O fanzine, através de uma rede de conexões de nível nacional e até internacional reforça essa representação mitológica sujeitando outros indivíduos que estão começando sua inserção no mundo do heavy metal, construindo assim, uma "comunidade imaginada" ${ }^{2}$. Sobre essa narrativa de um mito fundador Stuart Hall diz:

Essas fornecem uma serie de estórias, imagens, eventos históricos, símbolos e rituais nacionais que simbolizam ou representam experiências partilhadas, perdas, os triunfos e os desastres que dão sentido à nação. (...) há ênfase nas origens, na continuidade, na tradição e na intemporalidade. (HALL: 2006: $52-53)$.

Nesse sentido, podemos relacionar essa narrativa sobre a década de 1980 como o que Girardet chama de "era de ouro". Em relação a essa questão Girardet comenta:

\begin{abstract}
Alguns desses "tempos de antes" (...) foram efetivamente vividos antes de ter sido sonhados; sua imagem não faz mais do que sofre o habitual trabalho de inflexão, de seleção ou de transmutação que é a da lembrança. Outros, certamente os mais numerosos, escapam a memória individual por já não pertencerem senão à da história, ou do que passa por ser memória da história. O passado ao qual se referem nunca foi diretamente reconhecido; seu poder evocador é de um modelo, de um arquétipo (...) dominado pela noção primeira de queda, de degradação, esse movimento do sonho na direção de uma passado de Luz, mais feliz e mais belo, tende quase sempre cristaliza-se, fixa-se em torno de dois valores essenciais: valor de inocência, de pureza por um lado, valor de amizade, de solidariedade, de comunhão, por outro. É em função desses dois temas, na perspectiva dessa dupla busca ou dessa dupla nostalgia que toda mitologia da idade do ouro tende afirma sua coerência. (GIRARDET: 1987: 98-105).
\end{abstract}

Dessa maneira, a década de 1980 é entendida pelos headbangers como a "era de ouro" do heavy metal. Já a descrição da banda Steel Danger está inserida dentro da perspectiva que destacamos na citação acima, pois, o objetivo da banda é tocar um "heavy metal tradicional dos anos 80 , se engajando numa tentativa de resgatar a grande época que a cena teresinense viveu décadas atrás". Assim, busca-se novamente se adequar a um tempo que "nunca foi diretamente reconhecido".

\footnotetext{
${ }^{12}$ Para mais informações, ver: HALL, Stuart. A identidade cultural na pós-modernidade. Rio de Janeiro: 11 ed.
} DP\&A, 2006. 


\section{0: era de ouro?}

Mas porque a "era de ouro" dos headbangers foi à década de 1980? Bom, essa é uma questão que acreditamos ser muito ampla para ser plenamente respondida neste artigo, porém, podemos levantar alguns apontamentos sobre esse tema em relação à cidade de Teresina através do trabalho de Ernani Brandão ${ }^{13}$. No trabalho em questão podemos observar vislumbres sobre essa "era de ouro" na cidade de Teresina. Utilizando-se de matérias de jornais da década de 1980, Brandão destaca:

Entretanto, os jornais em Teresina deixam escapar outras matérias que
apresentam aspectos positivos do jovem roqueiro como as que dizem: Pouca
gente sabe que o Setembro Rock, que se realiza em Teresina é o maior
encontro de roqueiros do Norte-Nordeste, só superado pelo Rock in Rio (O
Estado, 1987). O Setembro Rock, é visto como um dos maiores eventos
culturais e musical do País (O Estado, 1986). Tais matérias destacam o
cenário de rock metal teresinense ao enfatizar a importância deste estilo
musical e ao mostrar o alcance dessa atuação com a propagação e a
valorização do festival Setembro Rock organizado pelos headbangers, nesta
cidade. O discurso da mídia revela ainda que, por causa do Festival
Setembro Rock, Teresina se tornou [...] palco de uma inusitada floração de
grupos de rock, que tem dado sinais de extrema vitalidade, refletindo
problemas urbanos e universalizantes. Destaca também que o festival é a
conquista deste espaço musical urbano (O Estado, 1985). (BRANDÃO JR:
2007: 63).

Com base nessa citação, podemos entender que o festival Setembro Rock foi um desses componentes da chamada "era de ouro" da cena heavy metal de Teresina. Toda via, é necessário levantar algumas questões sobre: primeiramente, a matéria jornalística deixa explicitamente seu teor propagandista. Nesse sentido, realizar um festival de rock é conectarse com certo ideal de modernidade, ou seja, uma configuração de novas identidades para os jovens piauienses. Outro ponto é: até que ponto o Setembro rock foi, de fato, aceito pelos os headbangers de Teresina? Sobre essa questão, ainda no trabalho de Brandão podemos identificar alguns indícios, pois:

(...) o Festival Setembro Rock não era direcionado somente para as bandas de rock metal, ele envolvia outros músicos de Teresina e do Piaú́. Essa mistura produzia shows com públicos bastante heterogêneos. Na época, o cenário de rock não tinha tantas divisões e subdivisões de estilos musicais,

\footnotetext{
${ }^{13}$ Ver: BRANDÃO JR, Ernani José. Headbanger: a produção histórica de uma subjetividade extrema. 2007.77 f. Monografia (graduação) - Centro de Ciências Humanas e Letras, Universidade Estadual do Piauí - UESPI, Teresina, 2007.
} 
de modo que tanto o hard rock (som mais pop e melodioso) quanto o rock heavy (som mais pesado) era entendido pelos roqueiros como rock 'n'roll. (BRANDÃO JR: 2007: 64).

Essa questão da não homogeneidade do festival Setembro Rock pode ser a primeira vista um aspecto irrelevante, porém, analisando os fanzines de heavy metal que circulavam em Teresina constatamos que os headbangers denominavam esse tipo de evento de "mistureba"14 (Denominação pejorativa usada para desqualificar os festivais que não eram exclusivos para bandas de heavy metal). Nesse sentido, podemos até fazer uma relação com o Rock in Rio, pois, o evento realizado em 1985 faz parte de uma narrativa que o coloca como um dos símbolos da redemocratização e da popularização do heavy metal no Brasil.

Porém, é necessário sempre desconfiar dessas narrativas canonizadas. Mesmo com vários discursos corroborando para a mítica do Rock in Rio, outras questões suscitavam acalorados debates entre os headbangers como, por exemplo, "o heavy metal nacional foi descaradamente excluído, mesmo tendo em suas fileiras um nome consagrado como Robertinho do Recife"15. Desse modo, entendemos o discurso no sentido "foucaultiano", pois:

(...) o discurso - a psicanálise mostrou-o —, não é simplesmente o que manifesta (ou esconde) o desejo; é também aquilo que é objecto do desejo; e porque - e isso a história desde sempre o ensinou — o discurso não é simplesmente aquilo que traduz as lutas ou os sistemas de dominação, mas é aquilo pelo qual e com o qual se luta, é o próprio poder de que procuramos assenhorearmos. (FOUCAULT: 1999: 10).

O discurso é uma "região", lugar que sintetiza determinados enunciados e dispositivos de poder. Nesse sentido, nem todos os enunciados, desejos entram na esfera do discurso. Apenas aqueles enunciados que, por condições historicamente postas, puderam emergir, dominam a "ordem do discurso". Assim, o discurso não é o simples reflexo do desejo, mas é acima de tudo, objeto que o desejo e o poder visam dominar, controlar e emitir sobre outros enunciados que não se constituíram enquanto discursos dominantes. Portanto, nem todos os enunciados sobre a primeira edição do Rock in Rio estão inseridos dentro de uma formação discursiva dominante, pois, os discursos são constituídos através de jogos de poder. Desse modo, é necessário compreender que o "mito metálico" da década de 1980 é

\footnotetext{
${ }^{14}$ Ver: NASCIMENTO, José Eduardo Oliveira. O cara mais underground é o diabo: representações, sentidos e subjetividades sobre o diabo no rock metal extremo de Teresina entre 2005-2017. 2018. 92 f. Monografia (Licenciatura Plena em História). Universidade Estadual do Piauí, Campo Maior, 2018.

${ }^{15}$ Trecho extraído da revista Metal, cujo acervo foi disponibilizado digitalmente através do site: $>$ https://www.brazilianassault86.com.br $<$
}

\section{Hilistorias}


uma construção histórica que poderá ser, futuramente, substituído por outro discurso mítico em suas páginas.

Outro fanzine que vamos analisar é o Metal of the nation. Em seu conteúdo identificamos muitas semelhanças com o fanzine Metal Warrior. No Metal of the nation identificamos muitos discursos sobre o heavy metal da década de 1980, inclusive, com uma frequência maior do que no Metal Warrior. Observem:

O HARPPIA, uma grande banda da década de 80 retornou com uma proposta verdadeira e honesta de fazer o bom e velho HEAVY METAL TRADICIONAL com muita personalidade e sem frescura.(...) Infelizmente a desunião ainda impera, salva rara exceções, ideias antigas como "Cooperativas do Rock" e eventos com moldes dos anos 80 já não funcionam mais... $(\ldots)^{16}$

O novo álbum levará o título de "Indestructors Ancient Armers", e terá 09 faixas incluindo uma instrumental de violão e teclado, sendo outras faixas o puro e insano Death metal com influencias oitentistas, e se desta vez tudo sair conforme desejamos o CD será lançado entre Outubro e Novembro. ${ }^{17}$

Formado no ano de 2001, o NO RACE surgi em São Paulo com o intuito de fazer um Thrash metal na linha oitentista (...) Farscape Thrash metal "Old school" (...) Thrash metal Old School Banda de Thrash metal influenciada pela saudosa época dos anos 80 que vem batalhando na cena underground para mostrar um trabalho sério e honesto $(. . .)^{18}$

Nas falas observou-se uma produção discursiva de uma que busca legitimar a década de 1980 e as bandas que surgiram nesse período como mais verdadeiro, honesto, ou seja, como autênticas representantes do heavy metal nacional. Além disso, é notório o sentimento de perda e sensação de decadência. Outro ponto interessante são os headbangers que não participaram diretamente da década de 1980, mas buscam constantemente remeter suas praticas "metálicas" a essa "era de ouro". Isso fica evidente quando a banda Zoltar que, apesar de praticar um estilo mais extremo de heavy metal, no caso o Death metal ${ }^{19}$, busca conectar o som da banda com a mítica década oitentista. Já o trecho que descreve as "bandas independentes" fica claro como esses sujeitos compartilham de técnicas de sujeição, buscando constante reforçar uma ligação com o mito oitentista. A banda NO RACE foi formada em 2001, mas para se legitimar perante aos outros headbangers diz na descrição produzir "um Thrash metal na linha oitentista”.

\footnotetext{
${ }^{16}$ Trechos extraídos da entrevista com a banda Harppia. Metal of the nation, N 8, 2003.

${ }^{17}$ Trechos extraídos da entrevista com a banda Zoltar. Metal of the nation, N 8, 2003.

${ }^{18}$ Trechos extraídos da sessão bandas independentes. Metal of the nation, N 8, 2003. Grifo do autor.

${ }^{19}$ Subgênero do heavy metal que tem como principais características a velocidade e o vocal gutural.
} 
Assim, os fanzines de heavy metal como "texto prescritivo", como um modo de sujeição para se adequar ao modus operandi dos verdadeiros headbangers. E, nesse sentido, repetir um conjunto de condutas que tem sua origem na década de 1980 que, estamos considerando, a "era de ouro" do heavy metal, pois, foi à década mitificada pelos headbangers.

\section{Considerações finais}

A partir dos fanzines de heavy metal analisados identificamos discursos que compõem uma narrativa mitológica sobre o heavy metal praticado na década de 1980. O período em questão é tratado como "era de ouro" pelos headbangers que, através de técnicas de sujeição, continuam a reproduzir um modus operandi baseado na estética visual e sonora das bandas oitentistas.

Toda via, é necessário mencionar que estamos cientes que existem outras possibilidades de ser/estar headbangers. Outras subjetividades podem existir além das que identificamos nos fanzines estudados. Porém, foi uma escolha metodológica, pois, acreditamos que é necessário um trabalho de maior fôlego para analisar as rupturas de uma "comunidade imaginada" tão contraditória como a dos headbangers.

Nesse sentido, nos atemos às continuidades em detrimento das descontinuidades, pois, o nosso objetivo específico foi analisar os discursos mitológicos sobre a década de 1980, através dos fanzines e como eles afetavam as práticas dos headbangers. Assim, por hora, a década de 1980 é o mito dos headbangers, porém, como toda construção histórica, outro "mito metálico" poderá emergir das páginas dos fanzines de heavy metal.

\section{Referências bibliográficas}

BRANDÃO JR, Ernani José. Headbanger: a produção histórica de uma subjetividade extrema. $2007.77 \mathrm{f}$. Monografia (graduação) - Centro de Ciências Humanas e Letras, Universidade Estadual do Piauí - UESPI, Teresina, 2007.

CASTELO BRANCO, Edwar de Alencar. Mídias táticas: os fanzines como fontes para a pesquisa histórica. In: Diálogos (Maringá. Online), v.19, n.2, p.741-762, mai-ago./2005.

Todos os dias de paupaeria: Torquato Neto e uma contra-história da tropicália. 2004. 289 f. Tese (Doutorado em História) - Universidade Federal de Pernambuco - UFPE, 2004.

A concepção de tempo histórico sob a História dos Annales: uma estratégia de evasão do 'tempo-terror. In: Interfaces de saberes, vol. 1, n. 2, João Pessoa, Idéia, janeiro a julho de 2001.

CAMPOY, Leonardo Carbonieri. Trevas na cidade: o underground do metal extremo no brasil. $2008.255 \mathrm{f}$. Dissertação (Mestrado em Sociologia e Antropologia) - Instituto de Filosofia e Ciências sociais, UFRJ, Rio de Janeiro, RJ 2008 
FOUCAULT, Michel. A ordem do discurso: aula inaugural no collège de france, pronunciada em 2 de dezembro de 1970. SAMPAIO, Laura Fraga de Almeida (trad). São Paulo: Edições Loyola, $5^{\circ}$ impressão, 1999.

. História da sexualidade: o uso dos prazeres. São Paulo: $5^{\circ}$ ed, Paz e Terra, 2018.

GIRARDET, Raoul. Mitos e mitologias políticas. São Paulo: Companhia das letras, 1987.

HALL, Stuart. A identidade cultural na pós-modernidade. Rio de Janeiro: 11 ed. DP\&A, 2006.

MAGALHÃES, Henrique. O que é fanzine. São Paulo, SP: Editora Brasiliense, 1993.

MUNIZ, Cellina (org). Fanzines: autoria, subjetividades e invenção de si. Fortaleza: Edições UFC, 2010.

NASCIMENTO, José Eduardo Oliveira. O cara mais underground é o diabo: representações, sentidos e subjetividades sobre o diabo no rock metal extremo de Teresina entre 2005-2017. 2018. 92 f. Monografia (Licenciatura Plena em História). Universidade Estadual do Piauí, Campo Maior, 2018.

REIS, José Carlos. Tempo histórico, história do pensamento histórico ocidental e pensamento brasileiro. Rio de Janeiro: FGV, 2012.

Tempo, história e evasão. Campinas, Sp: Papirus, 1994.

SILVA, Jaime Luis da. O heavy metal na revista Rock Brigade: aproximações entre jornalismo musical e produção de identidade. 2008. 128 f. Dissertação (Mestrado em Comunicação e Informação) - Faculdade de Biblioteconomia e Comunicação, Universidade Federal do Rio Grande do Sul, Porto Alegre, RG, 2008.

SILVA, Heitor Matos da. É que nossos corações preferem a auto-corrosão: uma história de vivências anarcopunks em Teresina (1980-2000). 2016. 128 f. Dissertação (mestrado em História do Brasil) Universidade Federal do Piauí - UFPI, 2016.

\section{FONTES}

Metal warriors maganize, Ed. 9 2014.

Metal of the nation, N 8, 2003.

Pecatório zine, ed.10 2012.

Sindicato dos assassinos, N 01, 2014. 